EVALUATION OF AN HIV AND AIDS SOCIAL INTERVENTION PROGRAMME FOR THE YOUTH IN THE NORTHERN CAPE, SOUTH AFRICA

André Rhyno Le Tape, Charlene Laurence Carbonatto, Lourens Stephan Geyer

The study focuses on a qualitative evaluation of the Soul City Social Intervention Programme (SCP) on HIV and AIDS targeted at the youth in the Northern Cape province, South Africa. The evaluation was implemented through a qualitative study, operationalised through an instrumental case study design. Data were collected through semi-structured interviews with 13 SCP field workers. Thematic analysis crystallised into two themes. Theme 1 focuses on the limitations regarding the implementation of the SCP, while theme 2 highlights the evaluation of the SCP from the field workers' perspective. Recommendations are made to improve the effectiveness of the programme.

Dr André Rhyno Le Tape, Postgraduate student, Department of Social Work and Criminology, University of Pretoria, Pretoria, South Africa.

Dr Charlene Laurence Carbonatto, Department of Social Work and Criminology, University of Pretoria, Pretoria, South Africa.

Prof Lourens Stephan Geyer, Department of Social Work and Criminology, University of Pretoria, Pretoria, South Africa.

André Le Tape, ORCID iD: 0000-0003-0724-2670

Charlene Carbonatto, ORCID iD: 0000-0002-0875-8903

Lourens Geyer, ORCID iD: 0000-0002-3765-3051

andre.rhyno@vodamail.co.za

Charlene.carbonatto@up.ac.za

stephan.geyer@up.ac.za

Keywords: evaluation, HIV and AIDS, social intervention programme, youth, field workers, Soul City Institute, Northern Cape, South Africa 


\title{
EVALUATION OF AN HIV AND AIDS SOCIAL INTERVENTION PROGRAMME FOR THE YOUTH IN THE NORTHERN CAPE, SOUTH AFRICA
}

\author{
André Rhyno Le Tape, Charlene Laurence Carbonatto, Lourens Stephan Geyer
}

Dr André Rhyno Le Tape, Postgraduate student, Department of Social Work and Criminology, University of Pretoria, Pretoria, South Africa.

Dr Charlene Laurence Carbonatto, Department of Social Work and Criminology, University of Pretoria, Pretoria, South Africa.

Prof. Lourens Stephan Geyer, Department of Social Work and Criminology, University of Pretoria, Pretoria, South Africa.

\section{INTRODUCTION}

HIV and AIDS are regarded as among the most significant humanitarian and developmental challenges facing the world today, with 37.9 million (between 32.7 and 44.0 million) people living with HIV across the globe in 2018, according to the Joint United Nations Programme on HIV/AIDS (UNAIDS, 2019:16), of which 1.7 million were children under 15 years. In September 2017 the US President's Emergency Plan for AIDS Relief (PEPFAR, 2017) supported 13.3 million people globally on lifesaving antiretroviral treatment (ART), enabled 2.2 million babies to be born HIV-negative to HIVpositive mothers, and supported 15.2 million males through the provision of voluntary medical male circumcision (VMMC).

The highest prevalence of adults and children living with HIV (UNAIDS, 2019:18) is in eastern and southern Africa at 20.6 million in 2018. In sub-Saharan Africa UNAIDS (2014b:5) found 26\% of adolescent girls compared to $36 \%$ adolescent boys have comprehensive and accurate knowledge about HIV, and only $15 \%$ of young women aged 15-24 are aware of their HIV status (UNAIDS:2014b:7).

UNAIDS (2019:62) reports South Africa (RSA) as having the largest epidemic in the world, with 7.7 million people living with HIV, of which $20.4 \%$ are aged $15-49$ years. As the number of young people aged 15-24 years increases globally, UNAIDS (2018) emphasises that efforts to provide HIV prevention services to meet the needs of the youth must be scaled up, if the world is to meet the global targets for reducing new HIV infections.

In the Northern Cape (NC), the research site of this study, the youth formed the largest portion of the population, according to Statistics South Africa (StatsSA, 2018), namely, the 15- to 34-year-old age group as the highest proportion of the NC population, at $34.8 \%$ in 2011 with a growth of $1.7 \%$ to $36.5 \%$ in 2016. Given the pandemic proportions of HIV among the youth, including the NC province, a study was deemed necessary to evaluate the Soul City Social Intervention Programme (SCP) for youth in the context of the National Strategic Plan (NSP) on HIV, STIs and TB 2012-2016 (NSP 2012-2016) of the South African National AIDS Council (SANAC, 2011).

This article offers a brief overview of the literature, followed by the theoretical framework underpinning the study. Next the problem statement, research question, aim, objectives and research methods of the study are outlined, followed by the findings, limitations, conclusions and recommendations.

\section{LITERATURE OVERVIEW}

The Soul City Institute (SCI) was established in 1992, with the National Head Office situated in Johannesburg, RSA. The vision of the SCI is "to ensure that society, communities and individuals have a right to live their best lives in an environment that is safe, supportive and sustainable" The Soul City Institute (SCI), 2019). The SCI has a track record of implementing successful social and behaviour change programmes at national, provincial community and individual levels (Nika, 2013a), achieved 
through multimedia edutainment vehicles and on-the-ground social mobilisation. These include the popular Soul City TV drama launched in 1994, radio drama and talk shows, and easy-to-read print materials.

The SCI has embraced a combination of preventative frameworks for HIV and AIDS prevention. The SCP mainly focuses on the following areas of HIV prevention amongst the youth: voluntary medical male circumcision (VMMC), prevention of mother-to-child transmission (PMTCT), education on avoiding multiple concurrent partnerships (MCP), and alcohol and risky sexual behaviour. Effective biomedical interventions are promoted and the demand is created through effective health communication, as it is recognised that HIV transmission occurs within the structural context of poverty, violence and alcohol abuse (Nika, 2013b).

Both the NSP 2017-2022 (SANAC, 2017) and the NSP 2012-2016 (SANAC, 2011) are considered social as well as public policies, developed by various government departments and stakeholders in response to the HIV pandemic facing RSA. To stem the tide of HIV and AIDS, the NSP 2012-2016 (SANAC, 2011) intends to improve the general welfare of individuals and communities at large and focuses on social problems such as HIV and its impact on society. Each province could develop its own provincial HIV and AIDS framework, as did the NC with the Northern Cape Provincial Strategic Plan for HIV \& AIDS (NCPSP), 2012-2016 (Department of Health (DOH), 2012). The NSP 2012-2016 (SANAC, 2011) aimed to inform national, provincial, district and community-level stakeholders on strategic directions to be taken into consideration when developing implementation plans. SANAC used it as framework to co-ordinate and monitor implementation by sectors, provinces, districts and municipalities. The NSP 2017-2022 (SANAC, 2017) similarly emphasises that the effective implementation of the NSP requires the involvement of all sectors - government, business, labour, civil society, development agencies, research institutions and communities.

The NSP 2012-2016 (SANAC, 2011:4) has four strategic objectives, and it is against this backdrop that the SCP was evaluated:

- Addressing social and structural factors that influence HIV, TB and STIs;

- Preventing new HIV, TB and STI infections;

- Sustaining health and wellness; and

- Protecting the human rights of people living with HIV.

In the RSA efforts to combat the pandemic are embedded in the National Development Plan (NDP) Vision 2030, which aims to increase the average life expectancy at birth to 70 years, as a result of positive improvements in evidence-based preventive therapeutic interventions for HIV (The Presidency, 2013). The NDP is aligned with the Sustainable Development Goals (SDG 3): 'Ensuring healthy lives and promoting well-being for all at all ages' (United Nations (UN), 2015). The NSP is closely aligned with the NDP, locating the struggle against HIV, TB and STIs within the broader struggle for economic and social development.

The youth were targeted in the implementation of the SCP as a vulnerable group. The Human Sciences Research Council (HSRC) (2017) found HIV incidence amongst all people in the RSA to be 14\% (7.9 million people living with HIV). The HIV and AIDS pandemic has affected all sectors of society in South Africa (RSA), particularly the youth. The HSRC (2017:39) reports 17\% (9 623 272) of the RSA population to be youths aged 15-24 years and 37.5\% (21 195 597) aged 25-49 years. StatsSA (2019) more recently found approximately one third of the RSA population ( total 58.8 million) at mid-year 2019 to be youths aged 18 to 34 years (17 840 000): 9.04 million males and 8.80 million females (StatsSA, 2019).

UNAIDS (2019:29) reports sexual debut before age 15 years in RSA from 2012-2016 to be $6 \%$ amongst female and $15 \%$ amongst male youths, with no parental consent policies regarding young people's access to sexual and reproductive health services in place. Furthermore, UNAIDS 
(2019:27;62) found in RSA from 2012 to 2018, among youths aged 15-24 years, that 82\% of sexually active females reported having high-risk sex, with $61.4 \%$ using a condom at their last sexual encounter, while $95 \%$ of sexually active males reported having high-risk sex, with $73.1 \%$ using a condom at the last sexual encounter. The prevalence of male circumcision (ages 15-49 years) in RSA was 57\% in 2017 (UNAIDS, 2019:63). The SCP focused on the mentioned aspects regarding HIV prevention.

\section{THEORETICAL FRAMEWORK}

An ecosystems perspective underpinned the present study. Ambrosino, Heffernan, Shuttlesworth and Ambrosino (2012) argue that the ecosystems perspective highlights the many roles social workers and related practitioners have to assume, either directly or indirectly, with the support of social programme implementers. For example, educating the community about parenting and HIV, and providing individual, family and group counselling to clients. Gray (2010) concurs that the ecosystems perspective points in the general direction of levels of possible intervention. It is therefore useful in the assessment of a social problem and provides a framework for analysing the interrelationship between individuals and social problems, such as the threat facing the youth regarding HIV and AIDS.

Germain and Gitterman (1986) deduced in their seminal work that adaptations are continuous, changeoriented, cognitive, sensory-perceptual and behavioural processes that people use to sustain or raise the level of fit between themselves and their environment, thus introducing the person-in-environment (or PIE) construct. Weyers (2011) advocates the value of a focus on individuals, their environment and the transactions or relationships between the two. It also explains the nature of social problems as a lack of adaptive fit within the PIE. For example, if there is an imbalance between the risk factors for HIV and adequate resources to support the youth, then social problems such as a rise in unhealthy sexual behaviours amongst the youth in a community might develop.

\section{Four environmental levels of the ecosystems perspective and the SCP}

Almost all countries in the developing world use some form of mass communication programme to address HIV and AIDS (Bertrand, O'Reilly, Denisson, Anhang \& Sweat, 2006). In line with ecosystemic thinking (Ambrosino et al., 2012), the SCP is discussed in the context of the micro, meso, exo and macro levels of people's environment.

\section{- Microsystem level}

The nurturing environment consists of the systems within which a person interacts frequently, having a profound effect on their sense of identity and functioning that contributes to or detracts from their social wellbeing (Weyers, 2011). Individuals and their nurturing environment are mostly the focus of micro-level practice, including individual casework services. The level incorporates the individual's level of functioning, intellectual and emotional capacities, motivation, the impact of life experiences, and the interactions and connections among individuals and others in their immediate environment. Examples of micro-level systems are a young person and their immediate family, parents, siblings, school or workplace. Makiwane and Mokomane (2010) found that despite the high levels of knowledge about HIV and AIDS, young people (15-24 years) in the RSA remain disproportionately affected by the epidemic.

Pettifor, O'Brien, MacPhail, Miller and Rees (2009) assert that race is in many respects a marker of former social disadvantage in RSA, and it still functions as a proxy for a host of sociocultural factors related to higher-risk sexual behaviours, such as residence in poor neighbourhoods, participation in labour migration, poor access to health information and services, and myths about the origins of HIV. The latter is confirmed by the HSRC (2017), namely, a finding was reached that HIV prevalence is much higher amongst Black Africans in South Africa, who historically were faced with the most severe socio-economic hardships in comparison to other racial groups.

\section{- Mesosystem level}


A mesosystem involves the relationship between microsystems that are linked by the significant other, who is present in both microsystems (Ambrosino et al., 2012; Spies, 2006). Because young people are part of families and schools, they normally provide a link between these two microsystems. The interactions in one microsystem therefore influence the interactions of the others (Ambrosino et al., 2012), for example, the person's home life may influence their school performance or confidence amongst peers (Spies, 2006). Both microsystems might have contrasting views, where the family is seen as a positive opportunity and negative peer influence as a risk.

\section{- Exosystem level}

The exosystem incorporates community-level factors that may not relate directly to the individual but affect the way individuals function. This includes factors such as the workplace policies (Ambrosino et al., 2012) of rural areas in the $\mathrm{NC}$ affecting the parents, e.g. if they cannot take compassionate family leave when their child is ill. Without family responsibility leave, the level of care and attention parents can provide is minimal.

Exosystemic intervention at the community level is often overlooked when facilitating planned change; however, it is critical when taking into account Whiteside's assertion (2000, cited in Maduze, 2002) that in RSA there have been cases where individuals deliberately have sex with virgins because of a myth amongst some individual community members that if a man has sex with a virgin, he will be cured of AIDS. This has led to a high incidence of HIV amongst young girls and children. In the RSA alone $20 \%$ to $25 \%$ of women who are HIV positive contracted the virus through being raped (Whiteside, 2000, in Maduze, 2002). In such a context community mapping and creation of 'safer social spaces' through the Phuza Wize Campaign of the SCI were used as a strategic exosystem intervention to prevent HIV infection through alcohol abuse and related gender-based violence within communities.

\section{- Macrosystem level}

The macrosystem level (societal level) consists of societal factors (Ambrosino et al., 2012), such as the cultural attitudes and values of society, for example, the stigmatisation of people infected by HIV. A lack of governmental programmes on HIV awareness contributes to the dire life situations of many young South Africans in certain communities. Examples of a macrosystem intervention would include change to legislation on belief systems (e.g. VMMC versus traditional circumcision). The influence of society is thus of paramount importance to the youth, who are highly susceptible to negative influences and misinformation, such as customary laws and belief systems or the stigmatisation of HIV.

Chambers and Wedel (2005) emphasise that accountability means that a programme must be able to be evaluated on achieving the objectives for the specified programme participants (in this case youths in the NC). The SCI monitoring thus had micro- meso- exo- and macro-level focus areas to ascertain whether the interventions were holistically effective, given the reciprocal interactive nature of different social environmental levels.

\section{PROBLEM STATEMENT, RESEARCH QUESTION, AIM AND OBJECTIVES}

Social work is one of the professions primarily tasked with addressing HIV programmes in communities. Furthermore, programme evaluation directed at the youth in the NC seems to be lacking, specifically concerning the implementation of the SCP. At the time of the study, the first author worked in the NC, which led to an awareness of the SCI implementing the SCP in two of the most densely populated districts in the NC, namely Frances Baard and John Taolo Gaetsewe districts, with high prevalence rates of youths with HIV. The HSRC (2017) confirms the importance of this SCI programme on HIV social and behavioural change communication in their report. HIV prevalence rates were confirmed as the highest in Frances Baard and John Taolo Gaetsewe districts (Nika, 2013b; SANAC, 2018). The rationale to evaluate the SCP regarding youth in the context of the NSP 2012- 
2016 (SANAC, 2011) in the NC was that youths formed the largest proportion of the population (StatsSA, 2018).

The authors confirmed a lacuna in the research by exploring a wide range of databases, including Sabinet, EbscoHost Africa-Wide, African Journal of AIDS Research Taylor \& Frances Online. As such, a research gap pertaining to the evaluation of the SCP for the youth in RSA was confirmed and practice guidelines could be provided for social workers to address future programmes focusing on HIV.

The research question that guided this study was: To what extent is the content and implementation of the Soul City Social Intervention Programme applicable to the youth in the NC, RSA?

This research aimed to evaluate the content, implementation and applicability of the SCP regarding HIV and AIDS targeted at the youth in the NC, RSA.

The objectives of the study specifically relevant to this article, are: (1) To evaluate the content of the SCI programme for the youth concerning HIV and AIDS in the NC in the context of the NSP 20122016 from the field workers' perspective; and (2) to provide guidelines for the content, applicability, implementation, monitoring and evaluation (M\&E) of the SCI programme for the youth concerning HIV and AIDS in the context of the NSP 2012-2016 to enhance efforts to mitigate the impact of HIV and AIDS among the youth in the NC.

\section{RESEARCH METHODS}

\section{Research approach and design}

The authors were particularly interested in the perceptions of the participants as expressed in their own words. Hence, the study was implemented within an interpretivist research paradigm (Nieuwenhuis, 2020). A qualitative research approach was adopted to undertake a process evaluation of the SCP with a focus on both the youth programme attendees and the SCP field workers. However, this article focuses exclusively on the qualitative data, obtained through the implementation of an instrumental case study design, which explored and described the viewpoints of SCP field workers on the implementation of the SCP (Creswell \& Poth, 2018).

\section{Research site}

The NC province spreads over $30.5 \%$ of RSA's landmass, being the province with the largest land area (372 889 square kilometres), but the smallest population (1 193 780) (StatsSA, 2018). There are no municipal metropoles and the province is divided into five districts, namely, Frances Baard, ZF Mgcawu, John Taolo Gaetsewe, Namakwa and Pixley ka Seme. This study was conducted in Francis Baard District (population 387 741), with 32,5\% of province's population, and John Taolo Gaetsewe District (population 242 264), with 20.3\% of province's population (StatsSA, 2018).

StatsSA (2018) found Black Africans to represent $65 \%$ and Coloureds $26.1 \%$ of the Frances Baard population, while Black Africans represent $83.5 \%$ and Coloureds $10 \%$ of the John Taolo Gaetsewe population, reflecting the different population distributions in these two districts included in this study.

\section{Study population and sampling}

The study population of field workers of the SCP in the NC consisted of all trained volunteers of the SCP, working at various NGOs in both Frances Baard and John Taolo Gaetsewe districts. SCI rendered programmes to the youth in both districts, hence no sampling method was implemented, as the entire population was recruited for the study. The Northern Cape Coalition had 17 field workers who were trained field workers of the SCP for the youth sector and specialising in HIV and AIDS. The whole population was targeted to be interviewed; however, only 13 provided informed consent to participate in the study (i.e. volunteer sampling) (Strydom \& Delport, 2011). 
Of the 13 participants, 10 were female and 3 male. Twelve (12) were African Black with Setswana as home language, while one (1) participant was coloured, with Afrikaans as home language. All participants were trained to facilitate Soul City dialogues with youths, with 2 participants permanently employed by SCI and 11 sub-contracted.

\section{Data collection}

Data were collected through semi-structured interviews, guided by an interview schedule. Interviews were audio-recorded with the participants' permission (Nieuwenhuis, 2020). The interview schedule consisted of open questions and probes which focused on the experience of the field workers on the implementation of SCP, as well as the contents, applicability, implementation, M\&E of the SCP. A probe such as the following was used: 'Can you describe the SCP you implemented with the youth?' Open questions such as the following were asked: 'Could you explain how you implemented the programme?'

\section{Data analysis and trustworthiness}

The thematic analysis process proposed by Braun and Clarke (2013) was used to analyse the data. The data-analysis process was comprised of six steps implemented in a cyclical and way and not necessarily linearly. In step 1 the audio recordings of the interviews were transcribed and the transcriptions were read and reread to identify items of interest. In step 2 the process of coding was undertaken for both latent and manifest content. The review of codes and 'upgrading' them to potential themes and subthemes formed step 3. In step 4 the themes and sub-themes were mapped and reviewed with the research question and the study's aim in mind. In step 5 the themes/sub-themes were given descriptive and self-explanatory names before report writing commenced (i.e. step 6) (cf. Braun \& Clarke, 2013). For this paper, two themes (with sub-themes) are discussed, namely the limitations of the SCP and evaluation of the SCP as expressed by the field workers.

The authors ensured the trustworthiness of the qualitative study, consulting colleagues and other professionals knowledgeable in the field of HIV and AIDS throughout the entire research process (i.e. peer debriefing), while confirming the findings with a selected number of participants (i.e. member checking). The first author and an independent person analysed the data independently; this was followed by a consensus meeting (i.e. observer triangulation) (Anney, 2014).

\section{Ethical considerations}

Permission to conduct the study was obtained from the management of the SCI and ethics clearance was obtained from the tertiary institution (Ref No. 12120554). The study ensured informed consent, with participants receiving a letter of informed consent before interviews commenced. The consent form focused on the aim, process of research, permission to record interviews, ensuring voluntary participation, confirming withdrawal from the study without any consequences and confidentiality being maintained, with their identity protected through the use of pseudonyms. Participants were debriefed after each interview to minimise any potential harm; however, no participant requested further counselling following the debrief (Babbie, 2017).

\section{FINDINGS AND DISCUSSION}

For this article two themes and sub-themes are presented as generated from the data.

Table 1 provides an overview of the themes and sub-themes. 
TABLE 1

THEMES AND SUB-THEMES

\begin{tabular}{|c|c|}
\hline THEMES & SUB-THEMES \\
\hline \multirow{8}{*}{$\begin{array}{l}\text { 1. Limitations } \\
\text { of the SCP }\end{array}$} & 1.1 Funding challenges \\
\hline & 1.2 Monitoring and evaluation (M\&E) tools \\
\hline & 1.3 Once-off dialogues \\
\hline & 1.4 Cultural resistance \\
\hline & 1.5 Political influence \\
\hline & 1.6 Gender stereotypes and discrimination \\
\hline & 1.7 Lack of SCI national support \\
\hline & 1.8 Lack of community support \\
\hline \multirow{5}{*}{$\begin{array}{l}\text { 2. Evaluation of } \\
\text { the SCP }\end{array}$} & 2.1 Evaluation by field workers \\
\hline & 2.2 Field worker reports \\
\hline & $\begin{array}{l}2.3 \text { Monitoring and evaluation (M\&E) of voluntary medical male circumcision } \\
\text { (VMMC) dialogue }\end{array}$ \\
\hline & 2.4 Contrasting views on monitoring and evaluation (M\&E) \\
\hline & 2.5 Outcome of evaluation \\
\hline
\end{tabular}

\section{Theme 1: Limitations of the SCP}

Limitations refers to what the participants experienced as limitations in implementing the SCP with the youths, as the subsequent sub-themes reflect:

\section{Sub-theme 1.1: Funding challenges}

The funding challenges included the following:

Because of funding, Soul City cannot do dialogues anymore because the funding was stopped by the funder. (Participant $\mathrm{B}$ )

Like we need to hire a hall and sometimes they delay us, Soul City delay about materials, about the money to send it, so we wait for a long time and the dialogues must be going on you see, so we wait, maybe let's stop for a month ... people, they are going to stop for a month. (Participant G)

The participants indicated a lack of sufficient funding by the SCI as a serious constraint that had farreaching implications for programme implementation. The challenges were in terms of the programme reaching all youths within the communities it operated in, programme accessibility for the youths, programme sustainability and its impact. The latter revelations are consistent with the SCI Annual Report (2014), which indicates that with a shift in geographical focus of the Centre for Disease Control and Prevention (CDC) midway through the year in 2013, SCI was informed that they were no longer able to support their work in the NC and North-West provinces, as they had decided to focus on different geographical areas.

This is also consistent with the view expressed by Healy (2008, in Kirst-Ashman, 2013) that many programmes do not survive past the term of outside grants, as they fail to consider the availability of funds on an on-going basis. Furthermore, the findings concur with Zewdie (2005), who found that a persistent challenge that must be addressed is that AIDS is still considered by many as a short-term crisis; hence, donors are reluctant to make long-term funding commitments, with donor funding remaining sporadic. It has to be emphasised that the SCP as functional HIV and AIDS youth prevention programme was not funded by the Department of Social Development (DSD), nor did it receive any other government funding. Furthermore, the financial demands of the ART programme put a strain on other aspects of the HIV and AIDS strategic plan, for example, advocacy and social awareness, the 
protection and promotion of human rights and intersectional collaboration (SANAC, 2011). The findings indicate how policy changes (exosystemic change) influence the implementation of the SCP.

\section{Sub-theme 1.2: Monitoring and evaluation $(M \& E)$ tools}

M\&E tools are essential for assessing the outcomes of programmes or services (Cloete, 2011). Participants shared as follows:

Exactly, we didn't have a monitoring tool at all, that's what I can say. I'm being honest. (Participant M)

Like I said, if we would do evaluation, then the stats would now be part of the evaluation in terms of saying from this community this what is happening, so much percentage of the people has really changed and so forth, you understand, because of what they saying because of we need to talk to them, you understand? So it also boils to the limitations in terms of the programme itself. (Participant B)

Participants emphasised a serious shortcoming in the SCP, namely lack of monitoring the effectiveness of the programme, which is consistent with the SCI Annual Report (2014), indicating that most provinces, for example the NC, were not part of M\&E processes of the SCP with the youth. The latter is in contrast with the SCI Annual Report (2013), which states that the SCI's vision is to improve people's health and quality of life by measuring the impact on health and development.

This sub-theme further highlights limitations often expressed in the literature and various government reports about HIV-prevention programmes. For example, Bautista-Arredondo, Bertozzi, Coutinho and Laga (2008) posed the question as to what extent national programme managers or international funders are guided by evidence of effectiveness, and they have found there are often no indicators to measure this directly. Rabie and Cloete (2011) confirm that social impacts are intangible phenomena that cannot always be measured directly and clear indicators need to be used for that purpose.

Zewdie (2005) states that historically many sub-Saharan governments were not fully committed to combatting HIV and AIDS, underscored by a lack of coordination between donors, insufficient funding and the lack of M\&E systems. Chatterjee and Vadapalli (2009) also caution programme developers, funders or implementers that a lack of acceptable and standardised outcome measures are key problems in programme impact analysis. UNAIDS (2014a) reiterates further that the Global Fund emphasises the importance of community systems strengthening (CSS), namely by strengthening local systems within communities in the fight against the spread of HIV, opportunities could be provided for the youth to play a key role in delivering peer-based and other health services.

\section{Sub-theme 1.3: Once-off dialogues}

Once-off means a single-type of intervention as opposed to a multipronged approach, which participants reflected on as follows:

People don't take it seriously, because if you come in and you go out, they forget or they see this as something that was passing. (Participant $\mathrm{B}$ )

It's [once-off dialogues] not working .... I think maybe when they come, at least may once in three months ... (Participant E)

The thing is, we cannot go into a community and just leave them like that, you know?... that's the problem. If there is no follow-up and there is no structure in place then for me I cannot say it's useless, but what I can say is that it's not doing itself justice. It's not helping enough. (Participant I)

These voices reflect how the field workers presented each dialogue with its focus area once-off, within an audience in either a particular community, or they presented a dialogue once in a community before moving on to the next community without ever returning. The International Organisation on Migration (IMO) (2011) defines sustainability as the ability of a programme or a project to continue and continue 
to be effective over the medium and long term. This should be strengthened through community ownership of the project and skills transfer. Sustainability should take into account financial sustainability, marketing and awareness building of programmes. Thus the once-off dialogues did not meet this definition.

\section{Sub-theme 1.4: Cultural resistance}

This sub-theme reflects a certain level of cultural resistance against certain aspects of the SCP amongst some community members:

It is a programme that needs to be implemented in communities and communities do differ. There were some cultural barriers that I would refer to as some limitations. (Participant C)

The other village where I stay as traditional chief and the other village is not interested in those traditional things .... Those did not interest, the others they were interested in the dialogue. (Participant F)

Participants identified a certain level of cultural resistance against certain aspects of the SCP amongst some community members. Goldstein (2016) refers to behavioural patterns and trends that frequently seem to be resistant to change and are sustained through various mechanisms, such as social norms and dominant cultural values. Van Dyk (2013) asserts that an AIDS-prevention programme in the African context cannot succeed easily without the support of traditional structures such as traditional healers. The NCPSP, 2012-2016 (DoH, 2012) also recognises the fact that some deeply rooted social, cultural, gender practices and human rights infringements influence HIV, STI and TB transmission negatively. The findings flag that social programmes may be resisted when the content is not in harmony with the macrosystemic level (e.g. cultural norms and values of a community).

The international organisation for migration (IOM) (2011) also indicates that identifying and targeting cultural gatekeepers, for example, traditional healers and leaders, is important in supporting and promoting social and behavioural change at the community level. Ross (2010) also adds that in many African cultural settings, the gender of the practitioner may be a significant factor in how the client system is likely to respond - for example, a female field worker addressing sensitive topics such as male circumcision and multi-concurrent sexual partners.

\section{Sub-theme 1.5: Political influence}

This sub-theme indicates, although to a lesser degree, how political instability or change at the time of SCP implementation can be a constraint:

In other communities, we meet people that are there not for progress or for not looking, for those people came up looking for their own agendas and we cannot run away from the fact that dialogues were done when we were, it was last year and we were all away April, May going for our national election so the mood, people mood were already activated that every person who calls a meeting should maybe address this thing with the information of [name of political party], during that time we had a tough time to get young people because it was like when you are recruiting young people you must be looking for to change their mindset to do [name of political party] thing ... political influence. If maybe [word unclear] and I want to do a dialogue in a community the leader is a [name of political party] it was hard. It's like who are you to come and speak to my people. (Participant $\mathrm{C}$ )

This participant reflected on some political issues hampering SCP implementation. Chambers and Wedel (2005) argue that once a programme or policy is implemented, it can become a problem for its earmarked groups of citizens, because of political influences that sometimes undermine the legislative processes that allow for social policies. Van Dyk (2013) concludes that AIDS-prevention programmes can be successful only if they are backed by political will. The NSP (2011), with aligned programmes such as the SCP, is an expression of the will of the people in a democratic society and should therefore not be denied implementation in a democratic society. 


\section{Sub-theme 1.6: Gender stereotypes and discrimination}

In the context of HIV, gender stereotypes and discrimination are real, as experienced by participants:

Instead of men. I'm not, maybe because men feel these issues are for women, only women should be doing that and I think it's also related to AZT. Only most females are going to the clinic to go and test, but men don't go there. (Participant A)

"Baie kere dan is dit maar net die vroue wat kom, die manne is mos nou rerig so ons meer manne betrek" [often it's only women that come to programmes, the men are rarely interested, so we should involve more men]. (Participant K)

It was clear from the thematic analysis that gender imbalances played a crucial role in the SCP programme reach. Bezuidenhout and Dietrich (2008) refer to gender stereotypes as women in certain cultural settings are often seen as potential victims and must be protected by parents and by society using laws and specifically geared programmes (i.e. macrosystemic consideration). This is also consistent with the finding of the HSRC (2017) that more HIV-negative females (45.0\%) were aware of their HIV status than HIV-negative males (35.6\%), indicating that there are significantly higher rates of HIV awareness and HIV testing among females, whether negative or positive, than among males. The awareness also links with provincial perceptions of risks, as the NC was ranked second highest in the proportion of people believing that they would not get infected with HIV (51.1\%). Knowledge also decreased in 2012 compared to 2008, for both Black African males (aged 25-49) and people who misuse alcohol (DoH, 2012).

Thus, it appears that macrosystemic issues have a great influence, for example the attitudes of males place females at considerable risk of becoming HIV infected by men, especially in male-dominated societies. Furthermore, in RSA, despite its progressive constitution, it is still found that because of their traditional 'lower status', females are not always empowered to negotiate for safe sexual intercourse through condom use, especially amongst the poorest in society. UNWOMEN (2015) furthermore highlights the fact that females living with HIV face numerous obstacles in participating meaningfully in HIV policy- and decision-making. These challenges may include stigma and discrimination, economic insecurity, and limited access to information and resources, as well as insufficient opportunities for development.

\section{Sub-theme 1.7: Lack of SCI national support}

The support from the SCI National Head Office to implement the SCP is reflected on as follows:

Because when I make some reports, give it to Soul City, Soul City doesn't give me back the answer, go there, do this and do this ... And can you just give one person from this company of Soul City, you come to us and explain more, because we don't know more, because I mean really, not that workshop that we had with Soul City, it was for a week workshop, so it was not good enough for us you see? (Participant D)

It was not easy because ther e was with the first visit there was a budget and then with the second with the follow-up, there was no budget, so I had to find my ways of dealing with that. (Participant C)

The sub-theme reflects very limited national support from the SCI National Head Office to assist with dialogue resolutions and ground-level supervision and support to field workers. Matheko (2016) of SCI Head Office indicated that thorough M\&E of SCP was impossible because of funding challenges. A social programme must have a specific geographic location, programme consultants and supervisors to guide the programme practitioners who are the most important element in programme implementation (Chambers \& Wedel, 2005).

\section{Sub-theme 1.8: Lack of community support}

The lack of community support was expressed as follows: 
Sometimes it was difficult because you will write maybe 100 people for that dialogues, so the community is the people that may not be participating in the dialogues, like maybe they can hear, but of the time comes when they were involved they did not come. (Participant $\mathrm{H}$ )

You know the councillor we have a challenge with when we invite them to our programmes, they don't come to them, in terms of getting the councillors to attend our programmes. (Participant A)

The participants' statements reflect poor attendance and participation in the SCP as a serious challenge. At times it was difficult to include key community role players and leaders in the dialogues. The finding is consistent with the literature in that there is increasing recognition that the meaningful participation of young people in HIV-prevention programmes is necessary if programmes are to respond to the needs and desires of young people and therefore be effective (Campbell, Gibbs, Maimane \& Nair, 2010). Ginsberg (2009) holds that local, community-based, community-run organisations have the best chance of overcoming certain problems that social welfare programmes are designed to reduce. Such structures could mediate between those in need and governments to solve problems with local solutions, and without solely relying on the large structures associated with national programmes, for example, SANAC. The finding highlights that for HIV social programmes to succeed, different systemic levels should have open communication among one other.

\section{Conclusion of Theme 1: Limitations of the SCP}

This theme revealed many limitations in terms of the SCP implementation and sustenance, as highlighted by participants. These included limitations in terms of funding, M\&E, the once-off dialogues used, cultural resistance, political influence, gender stereotypes and discrimination, lack of SCI national support and lack of community support. From an ecosystems perspective each environmental level has risks and opportunities, which can either assist in achieving positive social functioning or become a direct threat to, for example, the youths facing the environmental challenges of the NC pertaining to HIV and AIDS.

Furthermore, the PIE construct, as suggested by Weyers (2011), is especially valuable because of its focus on individuals and their respective environments, and the transactions or relationships between the two. For example, if there is an imbalance between the risk factors of HIV and AIDS and adequate resources in the NC to support the youth, social problems such as a rise in unhealthy sexual behaviours amongst the youth in a community might develop. The identified limitations expressed by participants presented a serious threat to the effectiveness and sustainability of the SCP and may have created a vacuum in the communities that it operated in. It also had the unintended consequence of alienating communities after trust and expectations had been built up. This may have happened especially after the programme was unexpectedly terminated in 2013, without the SCP apparently replacing it with alternative youth programmes.

\section{Theme 2: Evaluation of the SCP}

The following sub-themes reflect participants' practices regarding programme evaluation of the SCP.

\section{Sub-theme 2.1: Evaluation by field workers}

Participants shared their experiences of evaluating the SCP as follows:

The other one would be I'm not sure maybe it's not working, because of when it comes to evaluating, we do not do evaluating, you understand. If we did evaluate, it would mean go back to the community and finding out this programme, what has changed you understand, but we do not engage to the community again in terms of finding out what happened, what changed since the programme, what did the behaviour change from this point to this point. It comes back to the limitation in terms of finding out is the community progressing in terms of the information they get. (Participant A) 
Sometimes you meet this young girl ... just out somewhere in the community and will tell you "ous" [name withheld] we talk, since used their dialogue I've made some changes in my life. (Participant I)

$\mathrm{Na}$ 'n dialoog, hulle kom na my huis; hulle kom vrae my iets .... Ja ek sien die mense kom by my huis. [After the dialogue, they come to my house to ask more questions, ... yes I see the people come to my house]. (Participant J)

The participants' indicated they did not formally evaluate how beneficial the SCP was for the community. Their evaluation of the SCP included observing the youth attendees later in the community, sharing with field workers some benefits of attending the SCP, such as behaviour changes. Thus, the participants did not evaluate their SCP implementation in terms of constraints or benefits for the youth.

Potter (2008) asserts that usually when a programme is in operation, its recipients, managers, funding institutions and other stakeholders need to know whether it is beneficial to the communities, if it is effective and efficient, and if it is well planned to achieving the intended goals. UNAIDS (2014a) highlights further that it is important for stakeholders, for example, field workers, to know which norms, standards, laws and policies related to HIV prevention, treatment and care for adolescents and youth, might affect service delivery and treatment uptake among those in need in a particular country. This could also assist in M\&E of HIV prevention efforts. The finding signals how ineffective M\&E on the micro level (i.e. field workers) fails to influence policy (i.e. macro systemic level) with appropriate information to guide future programme development.

\section{Sub-theme 2.2: Field worker reports}

This sub-theme reflects on the monthly reports participants submitted to the SCI.

Just the attendance registers and so forth ....(Participant A)

Nee dit was mos maar net daai attendance registers [no, it was only the attendance registers].... (Participant $\mathrm{L}$ )

Most of the participants indicated that monitoring of programmes was limited to submitting reports on a specific session/dialogue to the SCI National Head Office at the end of every month. The targeted group size of the dialogues was at least 100 youths. The research findings reflected that most participants' monitoring of programmes was limited to having the youths who attended their programmes complete attendance registers, which they submitted with reports on a specific dialogue to the SCI National Head Office at every month end. Chambers (1981, in Rabie \& Cloete, 2011:208) argues that M\&E is often "quick-and-dirty", hence ineffective. The sub-theme revelations are consistent with the findings of Michel (2005) that there is a consensus that peer education is considered a 'valuable strategy,' but that it lacks sufficient reporting, monitoring and clear goals for most programmes.

\section{Sub-theme 2.3: Monitoring and evaluation (M\&E) of the voluntary medical male circumcision (VMMC) dialogue}

The M\&E of VMMC dialogue included:

Because at the clinic I saw some of the young people, they were fast, close to 100 young boys went to the clinic for medical male circumcision ...

(Participant F)

In terms of evaluating I would say that when we are doing VMMC, the only thing that we can say that get people from the dialogue that they go to the clinic .... (Participant A)

Participants reflected that many field workers used clinic statistics in terms of VMMC uptake as M\&E indicators for that specific dialogue topic, but had no M\&E system in place for other dialogues. This is 
in line with UNAIDS (2014a) indicating an $80 \%$ coverage target for VMMC which needed to be achieved by 2020. Chambers and Wedel (2005) indicate that if programme objectives cannot be measured, they are of little use in administering or evaluating a programme.

\section{Sub-theme 2.4: Contrasting views on monitoring and evaluation (M\&E)}

M\&E was reflected on as follows:

Our monitoring and evaluation unit within Soul City at the national office level .... (Participant B)

Exactly, we didn't have a monitoring tool at all, that's what I can say. I'm being honest .... (Participant M)

Like I said if we would do evaluation then the stats would now be part of the evaluation in terms of saying from this community, this what is happening, so much percentage of the people has really changed and so forth, you understand, because of what they saying because of we need to talk to them, you understand. So it also boils down to the limitations in terms of the programme itself. (Participant A)

Participants made mention of different SCI M\&E issues, such as that it is done by the SCI M\&E Unit based at the SCI National Head Office, but could not elaborate on their role; a session evaluation form was completed by youths who attended dialogues/sessions, but they did not do M\&E of their programmes at all.

From the diverse statements by the participants, there appeared to be a lack of clarity among all participants as to what $M \& E$ entails and whether they implemented it. An objective of $M \& E$ of a social programme is to establish whether it was effective in reaching its objectives (Potter, 2008). Rabie and Cloete (2011) assert that for programme outcomes to be evaluated, field workers should have a common understanding of outcome statements that should be specific in terms of the target group, the geographical area, the level of difference to be achieved and the time deadline for achieving the difference. Hence, the systemic levels should have open communication to benefit from $M \& E$ practices.

\section{Sub-theme 2.5: Outcome of evaluation}

Participants mentioned the following dialogue evaluation outcomes:

Yes, we do have reports that we send to our $M \& E$, we do have registers that we send to our $M \& E$ and the pledges that we send to $M \& E$ Unit ... every data go to Johannesburg. (Participant B)

The registers are just for people those who have been attending, give it to them [SCI national office], when I came back I just check which ages are good for coming to the dialogue .... The report is to show that I have been doing my work .... (Participant G)

These comments express limited evaluation outcomes, including the submission of registers and reports sent to the SCI National Head Office by SCP field workers. Thus the outcome of the dialogue evaluation was lacking.

The central goal of programme evaluation is to answer specific practical questions about social programmes and their development (Potter, 2008). These questions normally focus on programme implementation and outcomes, as well as on the quality of services provided. Programme evaluation is necessary to determine whether a human service is needed and likely to be used, whether it is conducted as planned and whether the human services do help people in need. Rabie and Cloete (2011) argue further that for evaluation to be effective, it must have significance in that it must make a difference to an existing situation, for example, HIV behavioural patterns amongst the youth. It must further have validity in that evaluation techniques and indicators should clearly and directly measure 
the performance intended to be measured. Effective evaluations should be written and undertaken objectively and evaluation results should be written clearly, with a practical problem-solving focus.

\section{Conclusion of Theme 2: Evaluation of SCP}

Findings from this theme revealed various contrasting views on the evaluation of the SCP: participant evaluations reflected no impact evaluation of the constraints or benefits of attending the SCP for the youth; monitoring of dialogues was limited to submitting facilitator reports of a specific dialogue to the SCI National Head Office at the end of every month, as well as attendance registers of how many youths attended each dialogue, with a perceived target of a minimum of 100 attendees; youth attendees filled in session evaluation forms; there was an M\&E Unit based at the SCI National Head Office, but they were unaware of the unit's role; and participants did not do M\&E of their programmes at all. Findings further revealed that field workers measured the impact of the dialogue on VMMC, specifically by inquiring on the uptake of youths going for VMMC at local clinics. However, concerning the latter, no formal statistics were kept or reported on by participants.

\section{LIMITATIONS OF THE STUDY}

The qualitative findings cannot be transferred to all SCI field workers in the RSA, as a small sample of field workers in one province was studied. However, the whole population of SCP field workers in the NC Province was sampled and well represented, with an $86.6 \%$ response rate. The strategies implemented to ensure the trustworthiness of the study may enhance the potential of the findings and recommendations to be utilised in similar contexts in the rest of the RSA.

\section{CONCLUSIONS}

The following conclusions respond the research question: To what extent are the content and implementation of the Soul City Social Intervention Programme applicable to the youth in the Northern Cape, South Africa?

The identified limitations of the SCP expressed by participants represent a serious threat to the effectiveness and sustainability of the programme and may have created a vacuum in the communities in which it operated, as well as the unintended consequence of alienating communities after trust and expectations may have been built up. This may have occurred especially after the programme was unexpectedly terminated in 2013 , as a result of the withdrawal of funding from sponsors, without apparently replacing it with alternative youth programmes by the SCP.

Management of the SCI, together with its funder, did not adequately plan for the financial sustainability of the SCP with the youth, or how its termination could sensibly be phased in, as all participants indicated that there is still a great need for the SCP within the communities in the NC. After its termination, and based on field workers' comments, the SCI may have created a level of frustration and unfulfilled community expectations, as this very relevant and applicable SCP programme, was supposed to be presented for a much longer a period than it was.

The SCP's once-off implementation was insufficient to sustain or build on attendees' knowledge and other needs, i.e. recreational or economic needs. From these identified limitations from an ecosystems perspective, it emerged that the youths consistently depend on their family (mesosystem) and their community resources (exosystem) to attain a healthy balance of fit when it comes to the risk factors associated with HIV and AIDS.

The SCP did not have an adequate M\&E system in place, or if it had, most field workers were unaware of it. The evaluation was limited to the level of the process of programme implementation on the days that dialogues were implemented, and were written in report form and submitted to the SCI National Head Office. No evaluation of programme impact in terms of monitoring and measuring negative behaviour change among the youth with regards to HIV as recipients of the programme was undertaken. 
Overall, participants did not adequately attempt to evaluate whether programme attendees understood the content of discussions, because there were no processes and systems in place to evaluate the impact in terms of behavioural change amongst the youths within the communities they serviced. This could be attributed to the lack of a formal monitoring tool in place, a lack of knowledge of what M\&E entails, and lastly, the single dialogue presentations within communities that the SCP operated in. Most participants were open to the idea that their interventions should be properly evaluated and they were eager to be skilled accordingly by the SCI.

There appears to have been a disconnection between traditional leaders' thinking and the predominant global HIV-prevention programme approach on matters to do with sex and safe sexual practices, especially in the NC. Finally, the focus of the SCP over-emphasised the exolevel, while completely neglecting the individual (microlevel) and/or mesolevel, which eventually may have strained the overall programme impact. Programme evaluation is thus necessary to determine whether a programme is conducted as planned and implemented eco-systemically in order to help youth in need.

\section{Despite the limitations highlighted, the authors conclude that the SCP contributed constructively towards the following strategic objectives of the NSP (SANAC, 2011:4), namely:}

- Addressing social and structural factors that influence HIV, TB and STIs;

- Preventing new HIV, TB and STI infections;

- Sustaining health and wellness.

\section{RECOMMENDATIONS}

The section conveys the recommendations made by the participants, as well those the authors would like to put forward.

Recommendations from field workers that social workers should consider when overseeing implementation of HIV programmes include:

- Specific youth programmes relevant to different age groups of young people should be available;

- More tools should be available for programme implementation;

- Formal evaluation tools should be introduced for field workers to use;

- Organisations implementing projects should remain in communities for longer periods;

- Other forms of youth support should be available besides once-off dialogues;

- The SCI National Head Office should increase its local-level involvement;

- More funding should be made available so that the SCP can be continued in all provinces;

- The local and provincial government should also provide financial support.

Recommendations made by the authors include:

- Liaise with relevant community leaders to explain the reason for the programme's involvement with the youth and related to HIV-prevention efforts to enhance their support of the programme;

- Future programmes should focus on forming specific age cohorts, such as youths aged 14 to 17 years, as they have different needs to those of youths 18 years and older;

- Future youth HIV and AIDS prevention programme content should be based on thorough situational analysis of communities targeted for programme implementation, and the analysis of impediments before developing local community-specific programmes for actual implementation;

- The youths came from various cultural and social environments and thus such programmes/interventions should be integrated with indigenous knowledge systems; 
- Adequate programme implementation and evaluation tools should be available and be distributed equitably across all provinces;

- Regular structured individual and group supervision and mentoring should be provided by the SCI to all field workers;

- Eco-systemic programme design and specification are essential for monitoring the quality of programme operations for the SCI to focus on in terms of HIV and AIDS amongst the youth;

- SCI Programme field workers ought to have a thorough understanding of the NSP as a macro-level influencing factor that contributed to the development of the SCP.

Furthermore, some recommendations for future social work research include:

- Determine what behavioural change the SCP contributed to amongst the youths who attended the programme;

- Determine the long-term impact of SCI field workers' involvement in the programme in terms of employment and work-related activities after the SCP;

- Determine the influence of culture in dealing with HIV risk factors in the RSA context, as this could enhance the understanding of cultural differences when dealing with HIV, sexual practices and youth risk factors.

The NSP 2017-2022 could guide all stakeholders in a collaborative effort to address HIV, TB and STIs, as it "serves as a roadmap for the next stage of the journey towards a future where these three diseases are no longer public health problems. This plan sets out the destinations or goals, of our shared journey and establishes landmarks in the form of specific measurable objectives" (SANAC, 2017:3).

\section{REFERENCES}

ANNEY, V.N. 2014. Ensuring the quality of the findings of qualitative research: Looking at trustworthiness criteria. Journal of Emerging Trends in Educational Research and Policy Studies, $5(2): 272-281$.

AMBROSINO, R., HEFFERNAN, J., SHUTTLESWORTH, G. \& AMBROSINO, R. 2012. Social work and social welfare: An introduction. $\left(7^{\text {th }} \mathrm{ed}\right)$. Belmont, $\mathrm{CA}$ : Thomson/Brooks.

BABBIE, E. 2017. The basics of social research. $\left(7^{\text {th }}\right.$ ed). Boston, MA: Cengage Learning.

BAUTISTA-ARREDONDO, A., BERTOZZI, S., COUTINHO, A. \& LAGA, M. 2008. Making HIV prevention programmes work. Lancet, 5(372):831-844. [Online] Available: http://www.thelancet.com [Accessed: 2012/10/25].

BEZUIDENHOUT, F.J. \& DIETRICH, V. 2008. Adolescent risk-taking behaviour. In: BEZUIDENHOUT, F.J. (ed). A reader on selected social issues. $\left(4^{\text {th }}\right.$ ed). Pretoria: Van Schaik.

BRAUN, V. \& CLARKE, V. 2013. Successful qualitative research: A practical guide for beginners. London: Sage.

CAMPBELL, C., GIBBS, A., MAIMANE, S. \& NAIR, Y. 2010. Mismatches between youth aspirations and participatory HIV/AIDS programmes in South Africa. African Journal of AIDS Research, 9(2):153-163. [Online] Available: htpp://dx.doi.org/10.2989/16085906.2010.517482. [Accessed: 2012/10/19].

CHAMBERS, D.E. \& WEDEL, K.R. 2005. Social policy and social programs: A method for the practical public policy analyst. $\left(4^{\text {th }} \mathrm{ed}\right)$. Boston: Allyn $\&$ Bacon.

CHATTERJEE, P. \& VADAPALli, D. 2009. The impact of social policy. In: Midgley, J. \& Livermore, M. The handbook of social policy. $\left(2^{\text {nd }}\right.$ ed $)$. Thousand Oaks, CA: Sage. 
CLOETE, F. 2011. Public policy in more and lesser developed states. In: Cloete, F. \& De Coning, C. (eds). Improving public policy: From theory to practice. $\left(3^{\text {rd }}\right.$ ed). Pretoria: Van Schaik.

CRESWELL, J.W. \& POTH, C.N. 2018.Qualitative inquiry and research design: Choosing among five approaches. $\left(4^{\text {th }}\right.$ ed). Thousand Oaks, CA: Sage.

DEPARTMENT OF HEALTH. 2012. Northern Cape Provincial Strategic Plan for HIV, TB \& STI's (NCPSP). 2012-2016. Kimberley: Government Printer.

GERMAIN, C.B. \& GITTERMAN, A. 1986. Social work treatment: Interlocking theoretical approaches. $\left(3^{\text {rd }}\right.$ ed). New York: The Free Press.

GINSBERG, L. 2009. Conservative approaches to social policy. In: MIDGLEY, J. \& LIVERMORE, M. The handbook of social policy. $\left(2^{\text {nd }}\right.$ ed). Thousand Oaks, CA: Sage.

GOLDSTEIN, S. 2016. Personal interview with Dr Sue Goldstein, National Director Soul City Institute, Johannesburg. [Transcript 2016/10/06].

GRAY, M. 2010. Theories of social work practice. 2010. In: NICHOLAS, L., RAUTENBACH, J. \& MAISTRY, M. (eds). Introduction to social work. Claremont: Juta \& Company Limited.

THE HUMAN SCIENCES RESEARCH COUNCIL (HSRC). 2017. South African National HIV Prevalence, Incidence, Behaviour and Communication Survey, 2017. Pretoria: HSRC.

INTERNATIONAL ORGANISATION FOR MIGRATION (IOM). 2011. Emerging good practices in migration HIV programming in Southern Africa. Pretoria: South Africa.

KIRST-ASHMAN, K.K. 2013. Introduction to social work and social welfare. Critical thinking perspective. ( $2^{\text {nd }}$ ed). Belmont, CA: Thomson Brookes/Cole.

MAKIWANE, M. \& MOKOMANE, Z. 2010. South Africa youth' high risk sexual behaviour: An ecodevelopment analysis. African Journal of AIDS Research, 9(1):17-24. [Online] Available: htpp://dx.doi.org/10.2989/16085906.2010.484538. [Accessed: 2012/08/12].

MATHEKO, M. 2016. Personal interview with Masemelo Matheko, Monitoring and Evaluation Unit of Soul City Institute [Transcript]. 6 October. Johannesburg: SCI.

MICHEL, B. 2005. Developing field generated standards of practice for HIV/AIDS peer education programmes for South African youth.. Johannesburg: University of the Witwatersrand. (Masters dissertation)

NIEUWENHUIS, J. 2020. Qualitative research designs and data gathering techniques. In: Maree, K. (ed.). First steps in research. $\left(3^{\text {rd }}\right.$ ed). Pretoria: Van Schaik.

NIKA, V. 2013a. Introduction letter to Soul City activities in the Northern Cape. E-mail: vuyi01@ hotmail.com to andre.rhyno@vodamail.co.za. (2013/08/27).

NIKA, V. 2013b. Personal interview with Mr Vuiyisie Nika, Provincial co-ordinator of the Soul City Programme in the Northern Cape, Kimberley. [Transcript 2013/08/27].

PEPFAR. 2018. PEPFAR - US President's Emergency Plan for AIDS Relief 2018 Report to Congress: 15 years of saving lives through American generosity and partnership. Washington, DC: US Dept. of State.

PETTIFOR, A., O’BRIEN, K., MACPHAIL, C.; MILLER, W.C.; \& REES, H. 2009. Early coital debut and associated HIV risk factors among young women and men in South Africa. International Perspectives on Sexual and Reproductive Health, 35(2):74-82. [Online] Available: htpp://dx.doi.org/10.1363/3508209. [Accessed: 2015/09/26]. 
POTTER, C. 2008. Programme evaluation. In: TERREBLANCHE, M.K., DURRHEIM \& PAINTER, D. (eds.). Research in practice: Applied methods for the social sciences. Cape Town: University of Cape Town Press.

RABIE, B. \& ClOETE, F. 2011. Policy evaluation. In: ClOETE, F. \& DE CONING, C. (Eds.). Improving public policy: From theory to practice. $\left(3^{\text {rd }} \mathrm{ed}\right)$. Pretoria: Van Schaik.

ROSS, E. 2010. Diversity and multicultural practice. In: NICHOLAS, L., RAUTENBACH, J. \& MAISTRY, M. (eds). Introduction to social work. Claremont: Juta \& Company Limited.

SANAC. 2011. The national strategic plan on HIV, STI's and TB 2012-2016. Pretoria: SANAC. [Online] Available: https://sanac.org.za/wp-content/uploads/2015/11/4-National-Strategic-Plan-forHIV-STIs-and-TB-2012-2016.pdf [Accessed: 2019/11/30].

SANAC. 2017. The National Strategic Plan for HIV, TB and STIs 2017-2022. Pretoria: SANAC. [Online] Available: https://sanac.org.za//wp-content/uploads/2017/06/NSP_FullDocument_FINAL.pdf [Accessed: 2020/04/01].

SANAC. 2018. The National AIDS Council Trust Annual Report 2017-2018. Pretoria: SANAC.

SOUL CITY INSTITUTE (SCI). 2019. History of SCI. Johannesburg: SCI. Johannesburg: SCI. [Online] Available: https://www.soulcity.org.za/about-us/history [Accessed: 2019/10/25].

SOUL CITY INSTITUTE (SCI): HEALTH AND DEVELOPMENT COMMUNICATION. 2013. Annual report. Johannesburg: SCI. [Online] Available: http://www.soulcity.org [Accessed: 2014/05/23].

SOUL CITY INSTITUTE (SCI): HEALTH AND DEVELOPMENT COMMUNICATION. 2014. Annual report. Johannesburg: SCI. [Online] Available: http://www.soulcity.org [Accessed: 2015/08/23].

SPIES, G.M. 2006. Sexual abuse: Dynamics, assessment, and healing. Pretoria: Van Schaik.

STATSSA. 2018. Provincial profile Northern Cape: Community Survey 2016. Report 030114. Pretoria: StatsSA. [Online] Available: http://cs2016.statssa.gov.za/?portfolio_page=community-survey2016-provincial-profile-northern-cape-2016 [Accessed: 2019/10/21].

STATSSA. 2019. Statistical Release P0302: Mid-year population estimates 2019. Pretoria: StatsSA. [Online] Available: http://www.statssa.gov.za/publications/P0302/P03022019.pdf [Accessed: 2019/11 /30].

STRYDOM, H. \& DELPORT, C.S.L. 2011. Sampling and pilot study in qualitative research. In: DE VOS, A.S., STRYDOM, H., FOUCHÉ, C.B. \& DELPORT, C.S.L. (Eds.). Research at grass roots: for the social sciences and human service professions. $4^{\text {th }}$ ed. Pretoria: Van Schaik.

THE PRESIDENCY. 2013. National Development Plan 2030 Our Future-Make it works. RP27/2011. Pretoria: Government Printers. [Online] Available: https://nationalplanningcommission.files.wordpress.com/2015/02/ndp-2030-our-future-make-itwork_0.pdf [Accessed: 2013/03/08].

United Nations (UN). 2015. Transforming Our World: The 2030 Agenda for Sustainable $\begin{array}{llll}\text { Development. NY UN. } & \text { [Online] Available: }\end{array}$ https://sustainabledevelopment.un.org/content/documents/21252030\%20Agenda\%20for\%20Sustainabl e\%20Development\%20web.pdf [Accessed: 2019/10/25].

UNAIDS. 2014a. Fast-track: Ending the AIDS epidemic by 2030. Geneva: UNAIDS.

UNAIDS. 2014b. The GAP Report 2014: Adolescent girls and young women. Geneva: UNAIDS. 
UNAIDS. 2018. The youth bulge and HIV. Geneva: UNAIDS [Online] Available: https://www.unaids.org/sites/default/files/media_asset/the-youth-bulge-and-hiv_en.pdf [Accessed: 2019/10/22].

UNAIDS. 2019. UNAIDS Data 2019. Geneva: UNAIDS. [Online] Available: https://www.unaids.org/sites/default/files/media_asset/2019-UNAIDS-data_en.pdf [Accessed: 2019/10/21].

UNWOMEN. 2015. Championing Gender equality in the HIV Response: The experience of five programme countries. 2015. Geneva: UN.

VAN DYK, A. 2013. HIV and AIDS education, care and counselling. A multidisciplinary approach. $5^{\text {th }}$ ed. Cape Town: Pearson.

WEYERS, M.L. 2011. The theory and practice of community work: A Southern African perspective. $2^{\text {nd }}$ ed. Potchefstroom: Keurkopie.

ZEWDIE, D. 2005. The HIV/AIDS epidemic in Africa: Implications for development. United Nations Commission on Population and Development. 5 April 2005. New York: United Nations. 